\title{
Massive hiatal hernia involving prolapse of the entire stomach and pancreas resulting in pancreatitis and bile duct dilatation: a case report
}

\author{
Hidenori Tomida* (D), Masahiro Hayashi and Shinichi Hashimoto
}

\begin{abstract}
Background: Hiatal hernia is defined by the permanent or intermittent prolapse of any abdominal structure into the chest through the diaphragmatic esophageal hiatus. Prolapse of the stomach, intestine, transverse colon, and spleen is relatively common, but herniation of the pancreas is a rare condition. We describe a case of acute pancreatitis and bile duct dilatation secondary to a massive hiatal hernia of pancreatic body and tail.

Case presentation: An 86-year-old woman with hiatal hernia who complained of epigastric pain and vomiting was admitted to our hospital. Blood tests revealed a hyperamylasemia and abnormal liver function test. Computed tomography revealed prolapse of the massive hiatal hernia, containing the stomach and pancreatic body and tail, with peripancreatic fluid in the posterior mediastinal space as a sequel to pancreatitis. In addition, intrahepatic and extrahepatic bile ducts were seen to be dilated and deformed. After conservative treatment for pancreatitis, an elective operation was performed. There was a strong adhesion between the hernial sac and the right diaphragmatic crus. After the stomach and pancreas were pulled into the abdominal cavity, the hiatal orifice was closed by silk thread sutures (primary repair), and the mesh was fixed in front of the hernial orifice. Toupet fundoplication and intraoperative endoscopy were performed. The patient had an uneventful postoperative course post-procedure.

Conclusion: A rare massive hiatal hernia, involving the stomach and pancreatic body and tail, can cause acute pancreatitis with bile duct dilatation. The etiology can be flexure of the main pancreatic and extrahepatic bile ducts. Symptomatic herniation is best treated with surgery. Elective surgery is thought to be safer than emergent surgery in patients with serious complications.
\end{abstract}

Keywords: Hiatal hernia, Pancreatitis, Hyperbilirubinemia, Abnormal liver function test

\section{Background}

Hiatal hernia $(\mathrm{HH})$ is a type of diaphragmatic hernia characterized by the prolapse of the contents of the abdomen sliding through the hiatal orifice into the mediastinum or the thoracic cavity. Elective surgical repair, traditionally, is the best recommended approach when the patient is symptomatic.

Prolapse of the stomach, transverse colon, small intestine, and spleen is relatively common, but that of the pancreas is a rare phenomenon. Acute pancreatitis and abnormal liver

\footnotetext{
* Correspondence: hidenori-tomida-920@shinshu-u.ac.jp Department of General Surgery, Asamananroku Komoro Medical Center, 3-3-21 Aioicho, Komoro, Nagano 384-8588, Japan
}

function test secondary to this phenomenon are particularly unusual. The etiology can be folding and resultant obstruction of the main pancreatic and extrahepatic biliary ducts to drainage.

We herein present an extremely rare massive $\mathrm{HH}$ involving the stomach and pancreatic body and tail that resulted in acute pancreatitis with bile duct dilatation and abnormal liver function test.

\section{Case presentation}

An 86-year-old woman with $\mathrm{HH}$ who complained of epigastric pain and vomiting was taken to our hospital. Her body weight, height, and body mass index were $51.2 \mathrm{~kg}$, 
$150.0 \mathrm{~cm}$, and 22.8, respectively. A physical examination of the patient revealed thoracic kyphosis. Her medical comorbidities include hypertension, diabetes mellitus, osteoporosis, and unruptured cerebral aneurysms. Computed tomography $(\mathrm{CT})$ performed 10 years prior to her admission showed a large type IV HH involving prolapse of the entire stomach and transverse colon (Fig. 1).

Blood examination results at her admission showed elevated levels of white blood cell $(13,700 \mathrm{U} / \mathrm{L})$ with $91 \%$ of neutrophils, elevation of serum amylase (2805 IU/L), transaminitis (alanine aminotransferase level of $76 \mathrm{U} / \mathrm{L}$, aspartate transaminase level of $213 \mathrm{U} / \mathrm{L})$, total $(2.0 \mathrm{mg} /$ $\mathrm{dL})$ and direct $(0.8 \mathrm{mg} / \mathrm{dL})$ bilirubin, alkaline phosphatase $(258 \mathrm{IU} / \mathrm{L})$, and gamma-glutamyl transpeptidase $(70$ $\mathrm{IU} / \mathrm{L})$. Arterial blood gas showed hypoxemia $(\mathrm{PaO} 262.6$ $\mathrm{mmHg})$. Enhanced CT (eCT) revealed a large type IV $\mathrm{HH}$ involving the entire stomach, and the body and tail of the pancreas sliding through the hiatal orifice into the mediastinum, with peripancreatic fluid in the posterior mediastinal space as a sequel to pancreatitis (Fig. 2). In addition, intrahepatic and extrahepatic bile ducts were seen to be dilated, and the latter was bended (Fig. 3). There was no gallstone or choledocholithiasis. Magnetic resonance cholangiopancreatography (MRCP) revealed dilated and bended distal main pancreatic and extrahepatic ducts (Fig. 4).

She was diagnosed with pancreatitis and abnormal liver function test as a complication of pancreatic herniation (Fig. 5). For the treatment of the acute pancreatitis, the patient received intravenous hydration, antibiotics (meropenem $1.0 \mathrm{~g}$ every $12 \mathrm{~h}$ ), gabexate mesilate (FOY) $600 \mathrm{mg} /$ day, and analgesics along with intensive care monitoring.

We tried endoscopic retrograde cholangiopancreatography (ERCP) to remove the obstruction of the bile

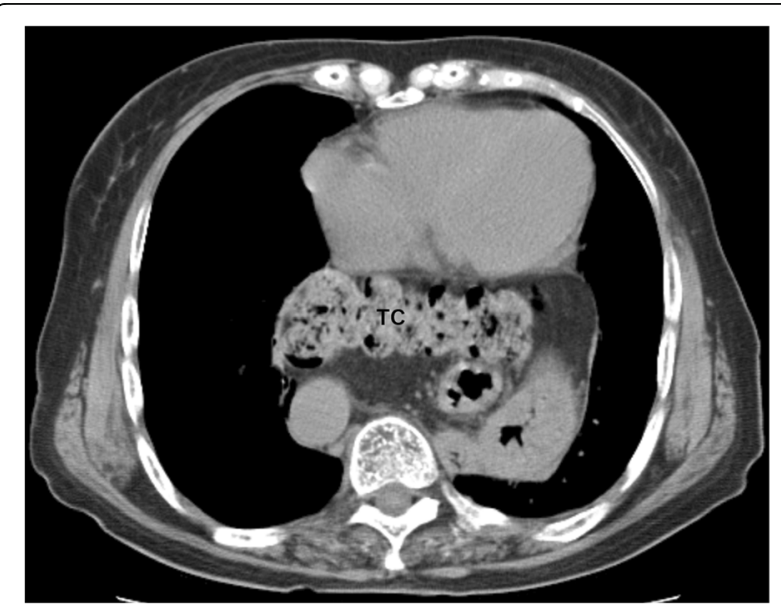

Fig. 1 Ten years earlier, the patient was noted to have a large $\mathrm{HH}$ involving prolapse of the entire stomach and transverse colon. TC: transverse colon duct, but we failed to perform papillary cannulation. Enteral nutrition via nasoduodenal tube was started on day 4 of hospitalization, and oral intake was started on day 10. During the treatment, hypoxemia progressed due to herniation of the stomach, which required oxygenation.

On day 36 of hospitalization, elective surgical repair of the $\mathrm{HH}$ was performed. During the laparotomy (Fig. 6), the stomach, omentum, and the contents of the hernia were mobilized into the abdominal cavity manually. There was a strong adhesion between the tail of the pancreas and the right diaphragmatic crus. The right pleura was damaged unexpectedly, which required closure and placement of a tracheal tube. After the stomach and pancreas were pulled into the abdominal cavity, the hiatal orifice was closed by silk thread sutures (primary repair), and the mesh was fixed in front of the hernial orifice. After Toupet fundoplication, intraoperative endoscopy was performed to confirm cardiac stenosis. The operative time was $217 \mathrm{~min}$, and intraoperative amount of bleeding was $830 \mathrm{~mL}$. The patient had an uneventful postoperative course.

$\mathrm{CT}$ on day 30 after the repair of the $\mathrm{HH}$ showed that the stomach, pancreas, and bile ducts were located in their normal anatomical position (Fig. 7). Due to pseudogout pain, her hospital stay was extended and she was discharged from the hospital 39 days after surgery without any symptoms of dysphagia. No dysphagia or recurrence of the hernia was observed at 6 months postoperatively.

\section{Discussion}

$\mathrm{HH}$ is a common disorder [1] characterized by the herniation of elements of the abdominal cavity into the chest through widening of the orifice of the diaphragm. Most small sliding HHs are asymptomatic. Patients with a large $\mathrm{HH}$ may have symptoms of chest pain, epigastric pain, indigestion, nausea, belch, cough, and shortness of breath [2].

As the mechanism of $\mathrm{HH}$ is not made completely clear, many theories are still being discussed. Weber et al. [3] described three dominant hypotheses of $\mathrm{HH}$, which are as follows: (1) increased intra-abdominal pressure that moves the gastroesophageal junction into the thorax cavity, (2) esophageal shortening from innate causes or acquired caused by fibrosis, and (3) widening of the orifice from innate or acquired changes in the crural muscles or connective tissue of the diaphragm.

Classification of $\mathrm{HH}$ has been attempted for the past several decades [4]. In the current anatomic classification, $\mathrm{HH}$ is divided into the following categories according to the extent of herniation and the location of the gastroesophageal junction: sliding hernia (type I), paraesophageal hernia (type II), mixed sliding and paraesophageal hernia (type III), and herniation of additional elements (type IV) [5, 6]. Most $\mathrm{HHs}$ are 

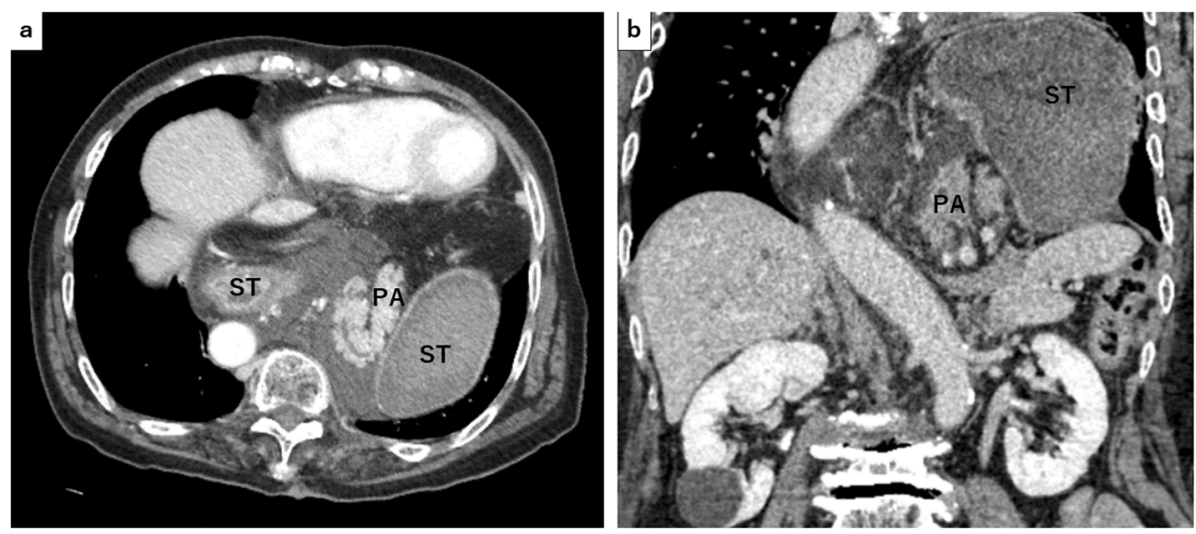

Fig. 2 Enhanced computed tomography (eCT) revealed a large $\mathrm{HH}$ involving the entire stomach and pancreatic body and tail sliding through the hiatal orifice into the mediastinum, with peripancreatic fluid in the posterior mediastinal space as a sequel to pancreatitis. In axial view (a) and in coronal view (b). ST: stomach, PA: pancreas

type I, and types II-IV are less common, accounting for $5-15 \%$ of cases [7].

Type IV HH is typically large and has both a sliding and paraesophageal constituent with diaphragmatic herniation of the abdominal elements, such as the stomach, transverse colon, small intestine, and spleen, which is relatively common. The symptoms of type IV HHs will also contingent upon the abdominal elements herniated through the orifice $[8,9]$. Sihvo et al. [10] claimed that fatal complications of $\mathrm{HH}$ were rare, which are mostly related to type III or IV in the elderly with serious complications in emergency surgery, and the small number of fatalities might have been prevented through an elective surgery. Jäger et al. [2] mentioned that serious secondary diseases of a type IV HH can occur when patients are treated conservatively; therefore, they recommend that all type IV HHs should be repaired as soon as possible after the diagnosis.
In type IV HH cases, pancreatic herniation is a rare phenomenon, because the head segment of the pancreas and duodenum are positioned in the retroperitoneum and fixed by Treitz' ligament [11]. However, extension of the transverse mesocolon owing to the increase in intraabdominal pressure induces loosening of the posterior fascia, which results in mobilization and herniation into the chest [12]. Herniation of pancreas can be without symptoms and found accidentally on imaging or as a sequel to acute pancreatitis. Acute pancreatitis as a sequela of this mechanism is very rare and has been previously reported in 13 patients [13-25]. Table 1 lists acute pancreatitis caused by the herniation of pancreas in $\mathrm{HH}$ from previous reports. Symptoms primarily consist of mostly abdominal pain and vomiting. Other manifestations include dyspnea, orthopnea, chest pain, diaphoresis, and weight loss.
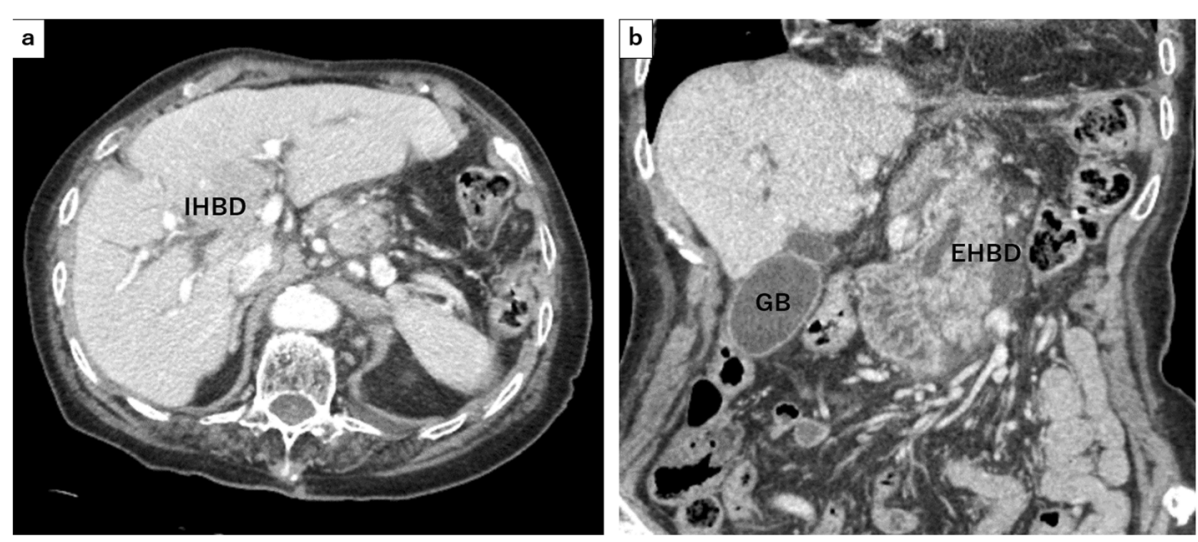

Fig. 3 Enhanced computed tomography (eCT) revealed that the intrahepatic and extrahepatic bile ducts were dilated, and the latter was bended. In axial view (a) and in coronal view (b). IHDB: intrahepatic bile duct, EHBD: extrahepatic bile duct, GB: gallbladder 


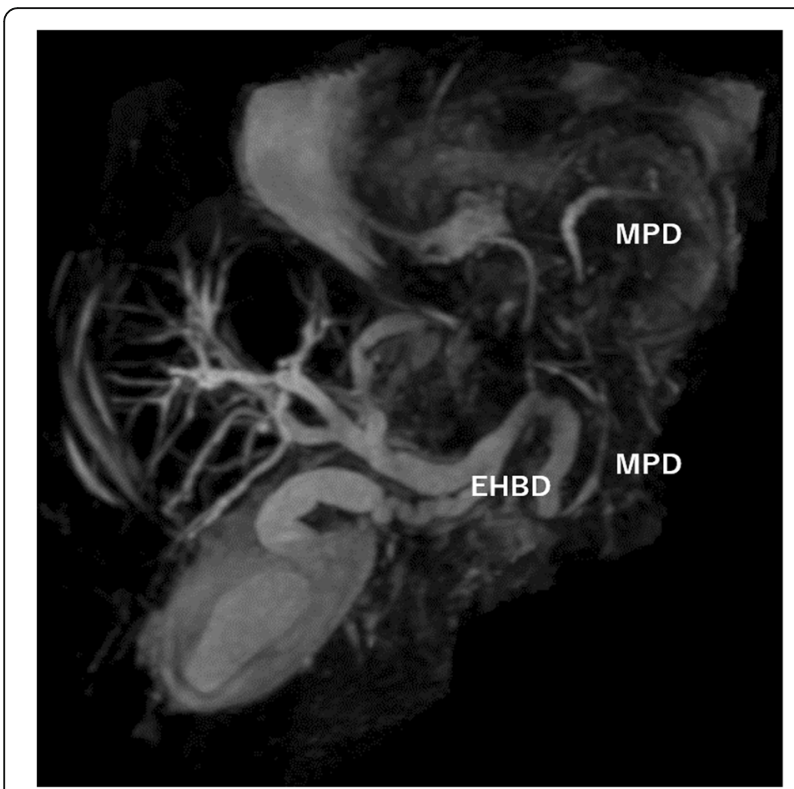

Fig. 4 Magnetic resonance cholangiopancreatography (MRCP) revealed dilated and bended distal main pancreatic and extrahepatic ducts. MPD: main pancreatic duct, EHBD: extrahepatic bile duct

The diagnosis is confirmed by elevation of pancreatic enzyme and imaging finding of pancreatic herniation with inflammatory reaction secondary to pancreatitis (peripancreatic fluid collections, interstitial edematous, stranding of mesenteric fat). Although it is difficult to

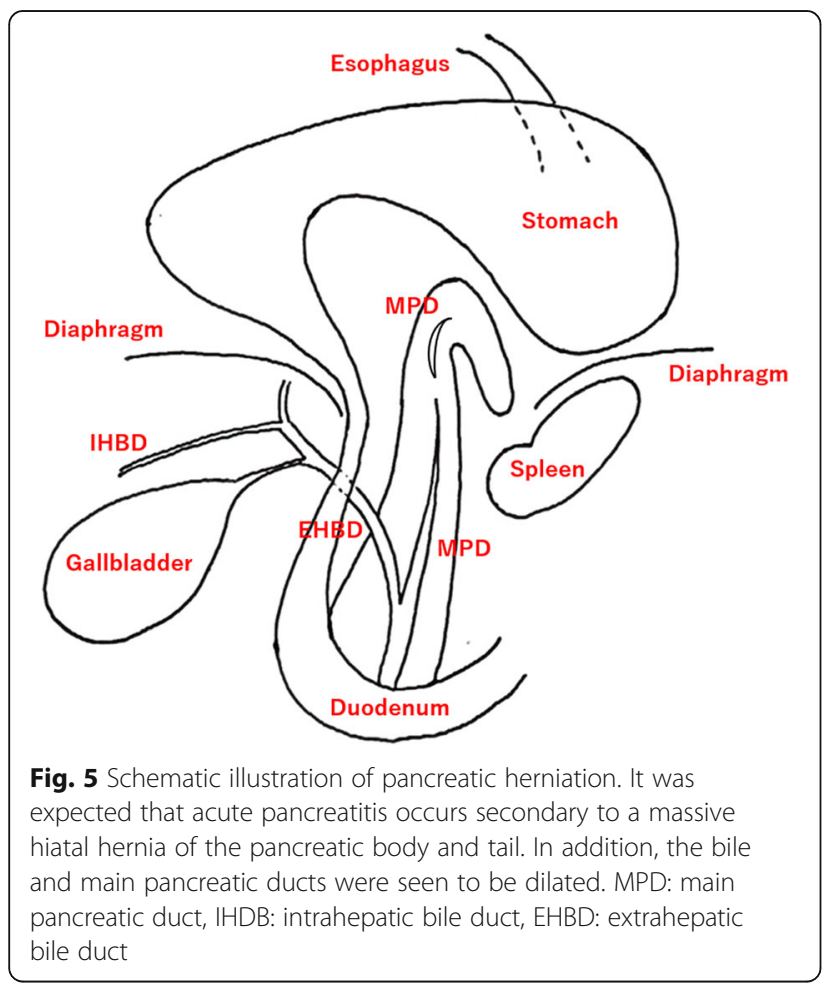

clearly prove that herniation of pancreas was the primary pathogenesis of acute pancreatitis, most cases were diagnosed based on the exception of other common pathogenesis for acute pancreatitis, such as gallstone, choledocholithiasis, and alcohol. Our case was diagnosed with acute pancreatitis based on symptoms, the presence of peripancreatic fluid detected on CT as a sequel to be secondary to pancreatitis, and elevated serum pancreatic enzyme level. The presence of type IV $\mathrm{HH}$ was found as the herniation of the transverse colon detected on CT 10 years earlier. The absence of typical risk factors of acute pancreatitis and the CT findings led us to predict the pathogenesis of our case's acute pancreatitis due to pancreatic herniation into the hiatal orifice.

The mechanism of pancreatitis due to herniation of the pancreas is presumed to be repeated damage of the pancreas and ischemia as a consequence of intermittent stretching of the blood vessels supplying the pancreas [26]. Another conceivable mechanism includes distortion of the pancreas, which impedes the normal pancreatic outflow, thereby leading to intraductal hypertension resulting in inflammation [12]. In such a case, extension of the transverse mesocolon may cause the lengthening of its posterior fascia and allow the mobilization of the pancreas [12]. In our patient, the duodenum and the head segment of the pancreas were still in place, probably remaining tightly fixed in the rear by Treitz' ligament. However, the mobilization of the body-tail segment may allow the herniation of the pancreas and bending of the parenchymal tissue, which caused the obstruction of the main pancreatic duct, as shown in the MRCP. Rarely, biliary stenosis due to herniation of a part of the duodenum results in cholestasis, requiring endoscopic retrograde cholangiopancreatography [11]. Yagi et al. [27] described a rare case in which prolapse of the entire stomach, head of the pancreas, and duodenum caused cholestasis.

Pancreatitis and obstructive jaundice occurring with $\mathrm{HH}$ are extremely rare. Jaundice may occur due to the distortion of the biliary tree, which occludes the extrahepatic bile duct. In Table 1, among the 14 cases, 5, 4, and 2 showed dilatation of the bile duct, transaminitis, and hyperbilirubinemia, respectively.

$\mathrm{HH}$ repair commonly includes the following four steps: hernia sac peeling and resection, mobilization of esophagus, repair of crus diagram, and fundoplication $[28,29]$. The use of mesh in crural repair has not been widely accepted, but when used, the absorbable mesh is most commonly selected [30-32]. Zhang et al. [33] confirmed that mesh repair may be associated with fewer short-term recurrences and that biological mesh was associated with improved short-term QOL; however, these advantages were offset by increased instances of dysphagia. In general, mesh is used as a counterfort of the 

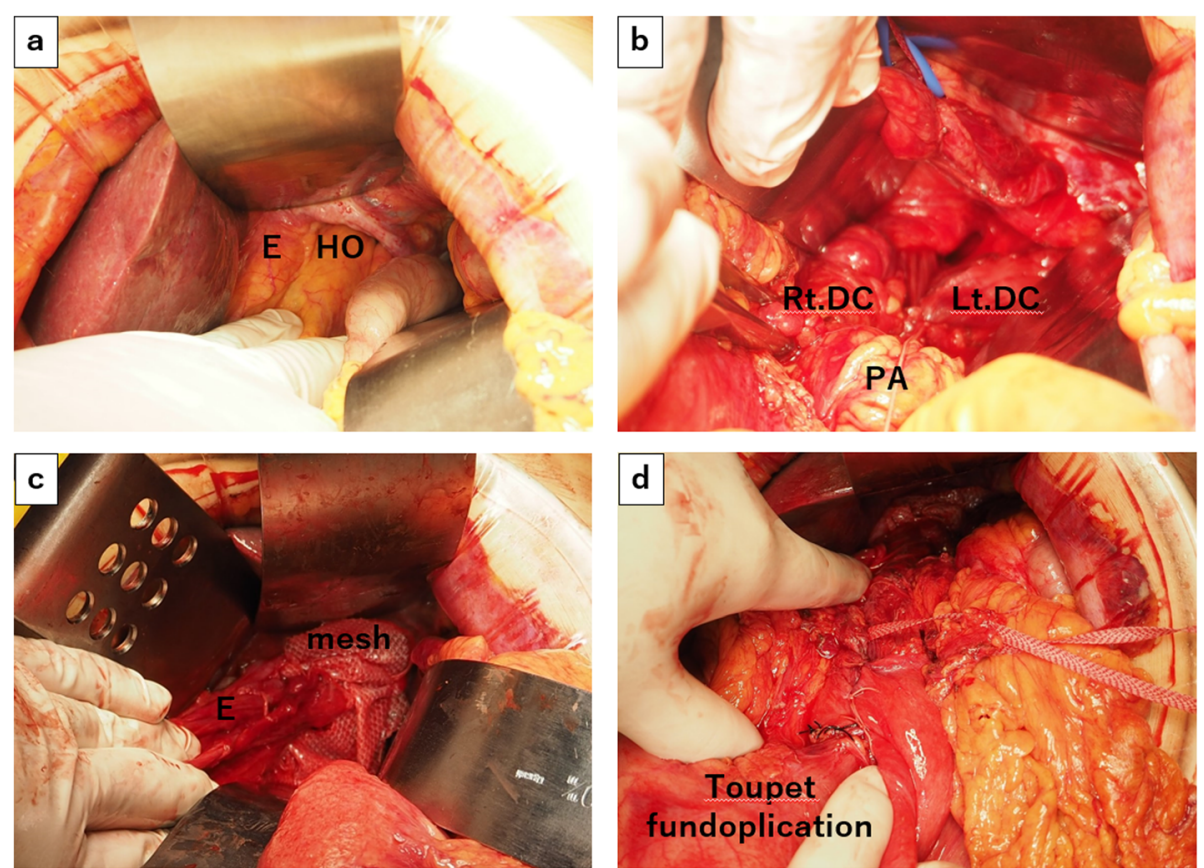

Fig. 6 Surgical procedure. a Surgical view through the incision. The stomach, omentum, and the contents of the hernia were mobilized into the abdominal cavity manually. E: esophagus, HO: hernial orifice. $\mathbf{b}$ There was a strong adhesion between the tail of the pancreas and the right diaphragmatic crus, and the right pleura was damaged unexpectedly, which required closure and placement of a tracheal tube. DC: diaphragmatic crus, PA: pancreas. c The hiatal orifice was closed by silk thread sutures (primary repair), and mesh was fixed in front of the hernial orifice; E: esophagus. d After Toupet fundoplication, intraoperative endoscopy was performed to confirm cardiac stenosis

hiatus orifice after primary suture, for the sake of withstanding the tension of the seam [1]. In our patient, when quick prevention of acute pancreatitis was paramount, we chose a mesh repair. To avoid postoperative dysphagia, we performed intraoperative endoscopy to confirm the patient was free of cardiac stenosis. The need for antireflux surgery in addition to $\mathrm{HH}$ repair has also been discussed. A randomized controlled pilot study from Muller-Stich et al. mentioned that fundoplication should be combined with a laparoscopic repair of $\mathrm{HH}$ to avoid postoperative gastroesophageal reflux [34]. The adaptation for surgical treatment is still debated. Owing to the risks of postoperative complications and the perioperative death of emergent surgery, traditionally, most
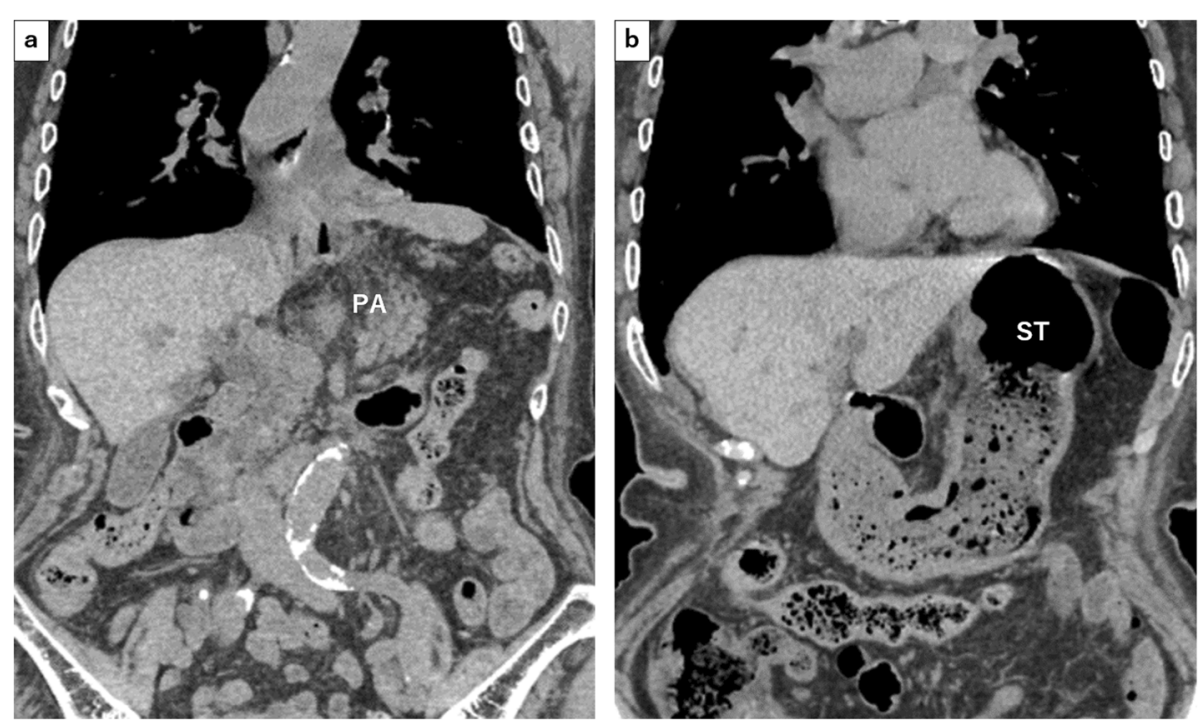

Fig. 7 a, b CT on day 30 after the repair of the HH showed that the stomach and pancreas were located in the abdomen. PA: pancreas, ST: stomach 
Table 1 Cases of acute pancreatitis caused by the hiatal hernia of the pancreas

\begin{tabular}{|c|c|c|c|c|c|c|c|c|}
\hline Number & Author & Year & $\begin{array}{l}\text { Age/ } \\
\text { sex }\end{array}$ & Transaminitis & Hyperbilirubinemia & $\begin{array}{l}\text { Area of pancreatic } \\
\text { herniation }\end{array}$ & Bile duct dilatation & Surgery pursued? \\
\hline 1 & Chevallier et al. [13] & 2001 & 70/M & ND & ND & $\mathrm{Pbt}$ & ND & Yes \\
\hline 2 & Laleman et al. [14] & 2008 & $80 / F$ & + & ND & Total & None & Yes \\
\hline 3 & Rozas and González [15] & 2010 & $78 / F$ & + & ND & $\mathrm{Pbt}$ & None & No \\
\hline 4 & Kumar et al. [16] & 2013 & $89 / \mathrm{M}$ & + & + & Pbt & $\mathrm{EHBD}$ & No \\
\hline 5 & Boyce et al. [17] & 2014 & $61 / \mathrm{F}$ & ND & ND & Phb & None & Yes \\
\hline 6 & Lal et al. [18] & 2015 & 70/F & ND & + & ND & EHBD & No \\
\hline 7 & Lu et al. [19] & 2015 & $88 / \mathrm{M}$ & - & ND & $\mathrm{Pbt}$ & None & No \\
\hline 8 & Patel et al. [20] & 2016 & $65 / M$ & ND & ND & Pbt & ND & No \\
\hline 9 & Wang et al. [21] & 2017 & $102 / F$ & - & ND & Pbt & None & No \\
\hline 10 & Shafiq et al. [22] & 2017 & $90 / F$ & - & - & $\mathrm{Pbt}$ & I/E HBD & No \\
\hline 11 & Do et al. [23] & 2018 & $65 / M$ & - & ND & $\mathrm{Pbt}$ & None & No \\
\hline 12 & Makhoul et al. [24] & 2018 & $24 / F$ & + & ND & ND & None & Yes \\
\hline 13 & Kamal et al. [25] & 2019 & $79 F$ & + & - & Pbt & I/EHBD & No \\
\hline 14 & Our case & 2019 & $86 / F$ & + & + & Pbt & I/E HBD & Yes \\
\hline
\end{tabular}

$M$ male, $F$ female, $P h b$ pancreatic head and body, Pbt pancreatic body and tail, IHDB intrahepatic bile duct, EHBD extrahepatic bile duct, $N D$ not described

surgeons decided to repair the $\mathrm{HH}$ whether the patient was symptomatic or not [35]. Hewitt-Taylor [1] confirmed that most symptomatic $\mathrm{HH}$ should be repaired, especially those with acute obstructive symptoms or those with distortion. Routine elective surgery of asymptomatic $\mathrm{HH}$ may not always be indicated. Consideration for $\mathrm{HH}$ surgery should include the age and basal disease. In our patient, strong adhesion due to pancreatitis was expected; thus, we decided to perform an open elective surgery.

Cases of pancreatic herniation with pancreatitis are rare; therefore, the ideal treatment is still unclear [20,21]. Some $\mathrm{HH}$ cases with pancreatitis were treated with surgery in the past $[13,14,17,24]$, but in other cases, physicians chose conservative treatment including administration of intravenous fluids, pain killers, and diet as tolerated because of high risk of surgery $[15,16]$ or patient's refusal to undergo operation [16, 18-21].

Considering the serious complications of type IV $\mathrm{HH}$, patients must be followed closely and undergo surgical repair early, after controlling the pancreatic inflammation, before serious complications occur.

\section{Conclusions}

Patients with a large $\mathrm{HH}$ may present with intermittent pancreatic volvulus. Although rare, this diagnosis of pancreatitis due to pancreatic herniation should be considered in patients with inexplicable pain associated with a large $\mathrm{HH}$. Moreover, the etiology can be flexure of the main pancreatic and extrahepatic bile ducts. Symptomatic herniation is best treated with surgery. Elective surgery is found to be safer than emergent surgery in a patient with a serious complication.

\section{Abbreviations}

$\mathrm{CT}$ : Computed tomography; eCT: Enhanced computed tomography; ERCP: Endoscopic retrograde cholangiopancreatography; HH: Hiatal hernia; MRCP: Magnetic resonance cholangiopancreatography

\section{Acknowledgements}

We would like to thank Editage (http://www.editage.jp) for English language editing.

Authors' contributions

$\mathrm{HT}$ wrote the draft of the manuscript. $\mathrm{MH}$ and $\mathrm{SH}$ revised the article. $\mathrm{MH}$ performed perioperative care. $\mathrm{MH}$ performed the operation. SH is a chief surgeon of our hospital and supervised the cases as well as the writing of the manuscript. All authors participated in the management of the patients in this case report. All authors read and approved the final manuscript.

\section{Funding}

None.

Availability of data and materials

All data generated or analyzed during this study are included in the published article.

\section{Ethics approval and consent to participate}

Not applicable.

\section{Consent for publication}

Consent for publication has been obtained from the patient presented in this case report.

\section{Competing interests}

The authors declare that they have no competing interests.

Received: 14 November 2019 Accepted: 31 December 2019

Published online: 09 January 2020

\section{References}

1. Hewitt-Taylor J. Guidelines for the management of hiatal hernia. The essential guide to doing a health and social care literature review. London: Routledge; 2018. p. 184-5.

2. Jäger T, Neureiter D, Nawara C, Dinnewitzer A, Ofner D, Lamadé W. Intrathoracic major duodenal papilla with transhiatal herniation of the 
pancreas and duodenum: a case report and review of the literature. World J Gastrointest Surg. 2013;5:202-6.

3. Weber C, Davis CS, Shankaran V, Fisichella PM. Hiatal hernias: a review of the pathophysiologic theories and implication for research. Surg Endosc. 2011;25:3149-53.

4. Barrett NR. Hiatus hernia: a review of some controversial points. Br J Surg. 1954;42:231-43.

5. Mitiek MO, Andrade RS. Giant hiatal hernia. Ann Thorac Surg. 2010;89:S2168-73.

6. Awais O, Luketich JD. Management of giant paraesophageal hernia. Minerva Chir. 2009:64:159-68.

7. Kahrilas PJ. Hiatus hernia causes reflux: fact or fiction? Gullet. 1993;3:21-30.

8. Mattioli S, D'Ovidio F, Di Simone MP, Bassi F, Brusori S, Pilotti V, et al. Clinical and surgical relevance of the progressive phases of intrathoracic migration of the gastroesophageal reflux disease. J Thorac Cardiovasc Surg. 1998;116:267-75.

9. Schieman C, Grondin SC. Paraesophageal hernia: clinical presentation, evaluation, and management controversies. Thorac Surg Clin. 2009;19:473-84.

10. Sihvo El, Salo JA, Räsänen JV, Rantanen TK. Fatal complications of adult paraesophageal hernia: a population-based study. J Thorac Cardiovasc Surg. 2009:137:419-24.

11. Suzuki K, Izumi Y, Ryotokuji T, Miura A, Kato T, Tokura M. Giant hiatal hernia with pancreatic prolapse: report of a case. SAGES. http://www.sages.org/ meetings/annual-meeting/abstracts-archive/giant-hiatal-hernia-withpancreatic-pro- lapse-report-of-a-case. Accessed 11 May 2019.

12. Kafka NJ, Leitman IM, Tromba J. Acute pancreatitis secondary to incarcerated paraesophageal hernia. Surgery. 1994;115:653-5.

13. Chevallier P, Peten E, Pellegrino C, Souci J, Motamedi JP, Padovani B. Hiatal hernia with pancreatic volvulus: a rare cause of acute pancreatitis. Am J Roentgenol. 2001;177:373-4.

14. Laleman W, Vanhoutte E, Vanbeckevoort D, Aerts R, Van Steenbergen W, Verslype C. A puzzling presentation of pancreatitis. Gut. 2008;57:1261,1278.

15. Rozas MG, González MM. A rare complication of hiatal hernia. Gastroenterology. 2010;139:e1-2.

16. Kumar P, Turp M, Fellows S, Ellis J. Pancreatic herniation: a rare cause of acute pancreatitis? BMJ Case Rep. 2013:2013:2-4.

17. Boyce K, Campbell W, Taylor M. Acute pancreatitis secondary to an incarcerated paraoesophageal hernia: a rare cause for a common problem. Clin Med Insights Case Rep. 2014;7:25-7.

18. Lal A, Gupta P, Sinha SK. An unusual cause of abdominal pain in an elderly woman. Gastroenterology. 2015;148:e11-2.

19. Lu LX, Payne M, Theobald CN. Education and imaging. Gastroenterology: diaphragmatic herniation and pancreatitis. J Gastroenterol Hepatol 2015;30:653.

20. Patel S, Shahzad G, Jawairia M, Subramani K, Viswanathan P, Mustacchia P. Hiatus hernia: a rare cause of acute pancreatitis. Case Rep Med. 2016;2016: 2531925.

21. Wang J, Thaker AM, Noor El-Nachef W, Watson RR. Transhiatal herniation of the pancreas: a rare cause of acute pancreatitis. ACG Case Reports J. 2017:4:e66.

22. Shafiq M, Badshah MB, Badshah MB, Badshah MB, Watkins J. Pancreas herniation into the mediastinum: a case report. BMC Res Notes. 2017;10:450.

23. Do D, Mudroch S, Chen P, Prakash R, Krishnamurthy P. A rare case of pancreatitis from pancreatic herniation. J Med Cases. 2018;9:154-6.

24. Makhoul E, El Mir J, Loutfi T, Assaf Y. Hiatal hernia and acute pancreatitis. Int J Curr Res. 2018;10:68298-300.

25. Kamal MU, Baiomi A, Erfani M, Patel H. Rare sequalae of hiatal hernia causing pancreatitis and hepatitis: a case report. World J Gastrointest Endosc. 2019;11:249-55.

26. Henkinbrant A, Decoster O, Farchakh E, Khalek W. Acute pancreatitis caused by a voluminous umbilical hernia. Case report Acta Gastroenterol Belg. 1989:52:441-7 [in French].

27. Yagi D, Takinami Y, Sugano M, Hattori Y. Laparoscopic repair of esophageal hiatal hernia with cholestasis secondary to pancreatic prolapse. Nihon Gekakei Rengo Gakkaishi. 2018;43:30-5.

28. Fisichella PM. A synopsis of techniques for paraesophageal hernia repair: different approaches to current controversies. Surg Laparosc Endosc Percutan Tech. 2013:23:423-4.

29. Patti MG, Fisichella PM. Laparoscopic paraesophageal hernia repair. How I do it. J Gastrointest Surg. 2009:13:1728-32.

30. Pfluke JM, Parker M, Bowers SP, Asbun HJ, Daniel SC. Use of mesh for hiatal hernia repair: a survey of SAGES members. Surg Endosc. 2012;26:1843-8.

31. Priego P, Perez de Oteyza J, Galindo J, Carda P, García-Moreno F, Rodríguez Velasco G, et al. Long-term results and complications related to Crurasoft mesh repair for paraesophageal hiatal hernias. Hernia. 2017;21:291-8.
32. Jones R, Simorov A, Lomelin D, Tadaki C, Oleynikov D. Long-term outcomes of radiologic recurrence after paraesophageal hernia repair with mesh. Surg Endosc. 2015;29:425-30.

33. Zhang C, Liu D, Li F, Watson DI, Gao X, Koetje JH, et al. Systematic review and meta-analysis of laparoscopic mesh versus suture repair of hiatus hernia: objective and subjective outcomes. Surg Endosc. 2017;31(12):491322. https://doi.org/10.1007/s00464-017-5586-x.

34. Muller-Stich BP, Achtstatter V, Diener MK, Gondan M, Warschkow R, Marra F, et al. Repair of paraesophageal hiatal hernias-is a fundoplication needed? A randomized controlled pilot trial. J Am Coll Surg. 2015;221:602-10.

35. Lebenthal A, Waterford SD, Fisichella PM. Treatment and controversies in paraesophageal hernia repair. Front Surg. 2015;2:13.

\section{Publisher's Note}

Springer Nature remains neutral with regard to jurisdictional claims in published maps and institutional affiliations.

\section{Submit your manuscript to a SpringerOpen ${ }^{\circ}$ journal and benefit from:}

- Convenient online submission

- Rigorous peer review

- Open access: articles freely available online

- High visibility within the field

- Retaining the copyright to your article

Submit your next manuscript at $\boldsymbol{\nabla}$ springeropen.com 